\title{
THE CREEP AND FATIGUE BEHAVIOR OF HAYNES 282 AT ELEVATED TEMPERATURES
}

\author{
Sara C. Longanbach and Carl J. Boehlert \\ Michigan State University, Department of Chemical Engineering and Materials Science, East \\ Lansing, MI 48824
}

Haynes 282 is a wrought, gamma-prime strengthened nickel-based superalloy intended for use in high temperature structural applications. In order to investigate processing-microstructureproperty relationships, the microstructure and elevated-temperature creep and fatigue behavior of Haynes 282 were evaluated after it had been processed using strain-recystrallization thermomechanical treatments. These treatments included a sequence of $20 \%$ cold rolling steps followed by recrystallization annealing. Microstructural evaluation was performed using scanning electron microscopy (SEM) and electron backscattered diffraction (EBSD). Figure 1(a) illustrates the microstructure after the thermomechanical processing treatment. From the collected EBSD data, the number fraction of certain boundary types was determined. General high angle boundaries (GHAB) accounted for $38 \%$ of the boundaries, while low angle boundaries (LAB) accounted for $4 \%$. $58 \%$ of the boundaries were coincident site lattice boundaries (CSLB) and it is noted that $47 \%$ of the overall boundaries were twins $(\Sigma 3)$. The majority of the boundaries were categorized as CSLB+LAB, and these have been associated with enhanced creep resistance for other superalloy systems. The creep and fatigue properties at elevated temperatures $\left(760^{\circ} \mathrm{C}-815^{\circ} \mathrm{C}\right)$ of this alloy were examined and compared to the results obtained for two solid solution-strengthened superalloys, nickel-based Haynes 230 and cobaltbased Udimet 188. Figure 2 compares the creep behavior for the alloys and it is evident that the Haynes 282 is the most creep resistant. The measured creep exponents (n) (Figure 2) for each of the alloys suggest that similar creep deformation mechanisms may be active. Figure 3 (a) illustrates a plot used to calculate the $Q_{\text {app }}$ values for Haynes 282 at different stresses. It is expected that the dominant secondary creep mechanism was dislocation climb and this will be evaluated using TEM of the deformed samples. The strain-life history of the fatigue experiments revealed that creep contributed to the total strain accumulated in the samples; see Figure 3 (b). The Young's modulus decreased during fatigue testing indicating that damage likely occurred during these experiments. The creep-fatigue synergisms and deformation mechanisms will be evaluated using electron microscopy. 


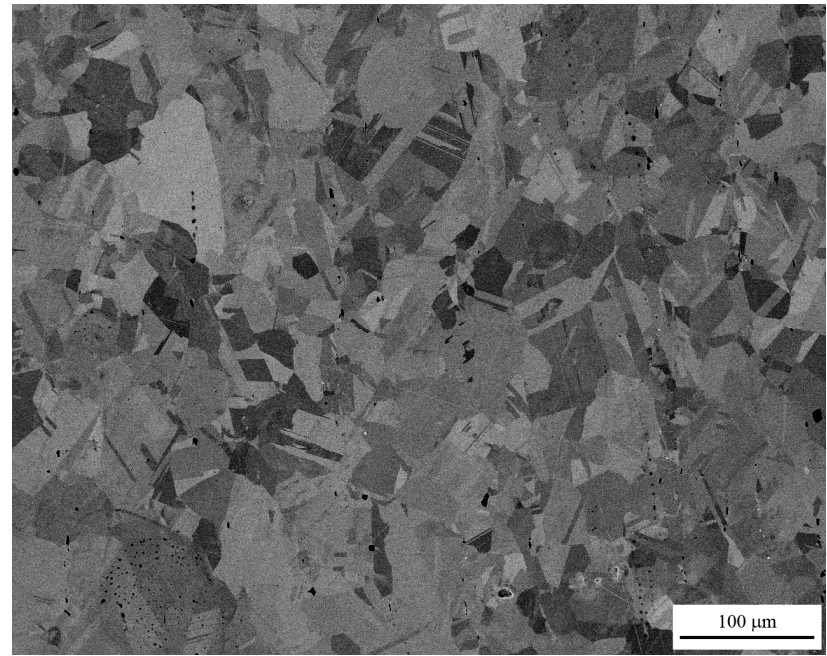

(a)

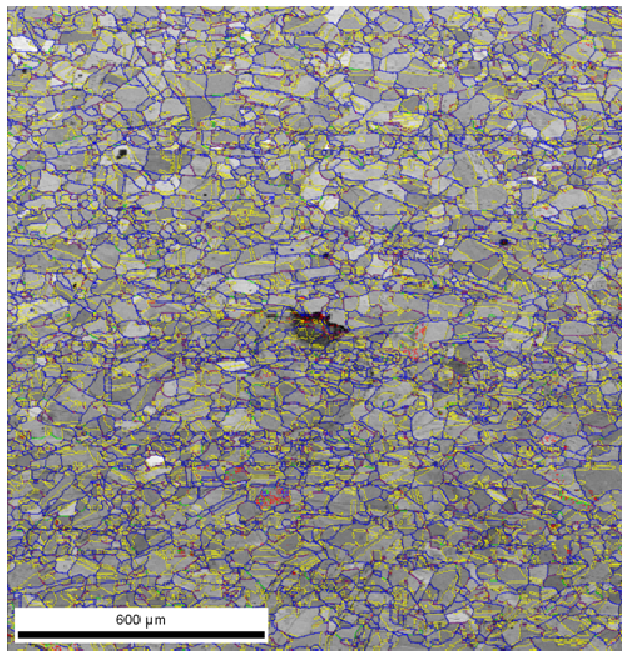

(b)

Figure 1. (a) BSE SEM image of Haynes 282 microstructure before the age-hardening heat treatment and (b) an EBSD image quality map highlighting the distribution of grain boundary misorientations $\left(\right.$ red $\left(2^{\circ}-5^{\circ}\right)$ and green $\left(5^{\circ}-15^{\circ}\right)=\mathrm{LAB}$, blue $=$ GHAB, purple $=$ CSLB (excluding $\Sigma 3$ ) and yellow $=\Sigma 3$ ).

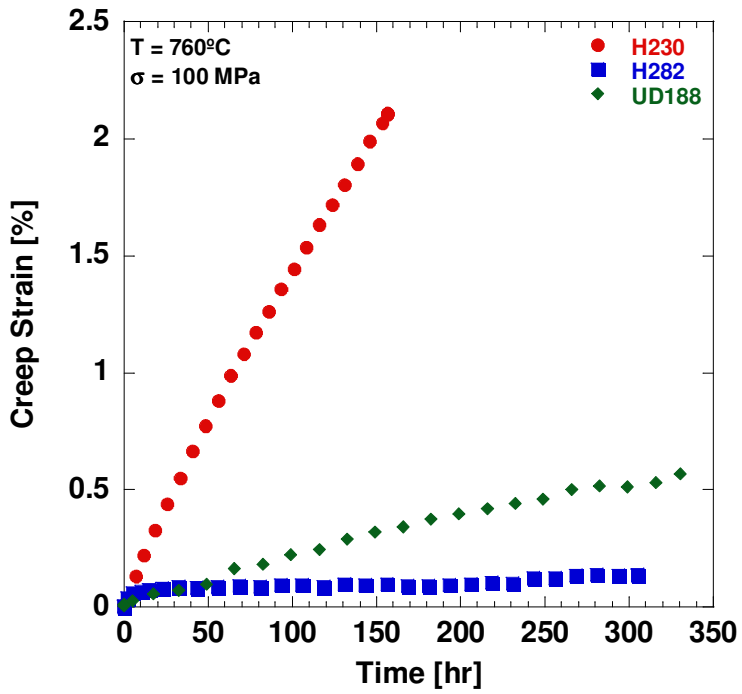

(a)

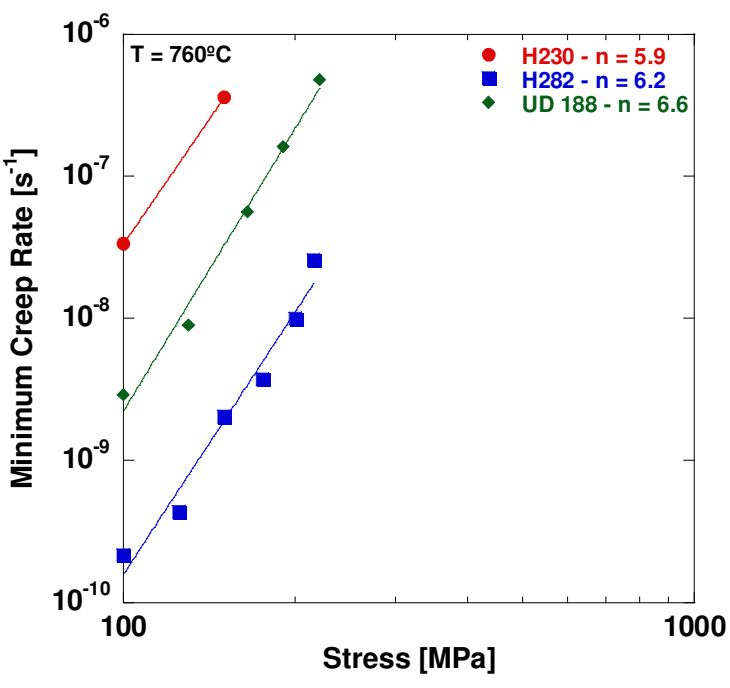

(b)

Figure 2. (a) Creep strain versus time plot $\left(\mathrm{T}=760^{\circ} \mathrm{C}\right.$ and $\left.\sigma=100 \mathrm{MPa}\right)$ and (b) minimum creep rate versus stress plot to determine the creep exponent value (n) at $\mathrm{T}=760^{\circ} \mathrm{C}$ for Haynes 230 , Haynes 282 and Udimet 188. 


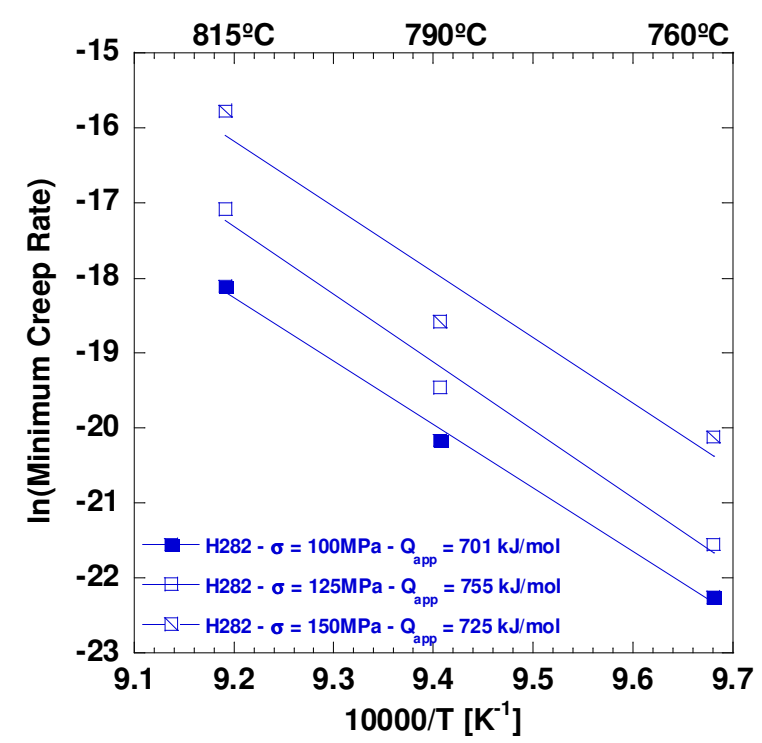

(a)

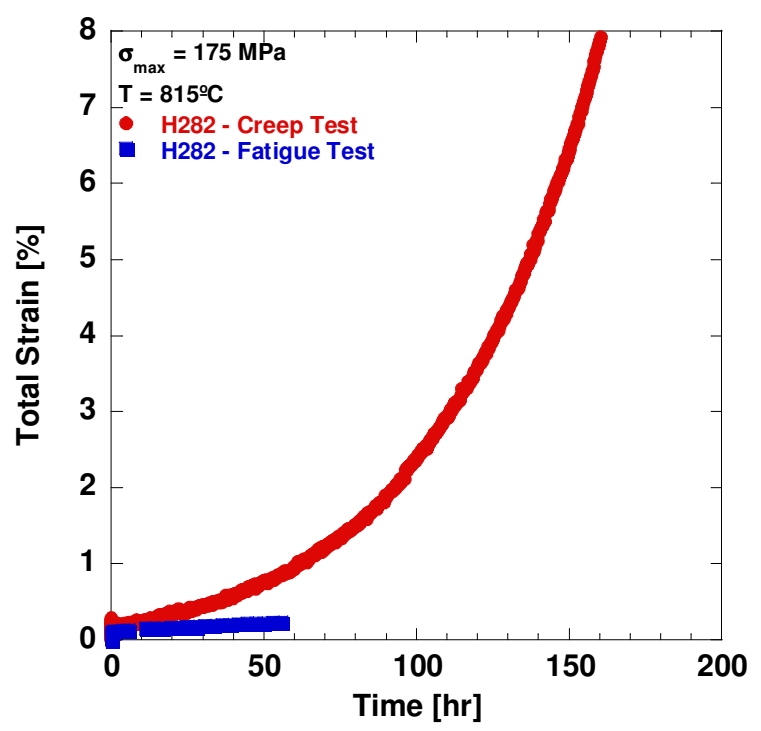

(b)

Figure 3. (a) $\ln$ (minimum creep rate) versus 10000/T plot used to caluculate $Q_{\text {app }}$ value for Haynes 282 at three different creep stresses and (b) strain versus time plot during a loadcontrolled fatigue experiment $(\mathrm{R}=0.1)$ at a maximum applied stress of $175 \mathrm{MPa}$ at $\mathrm{T}=$ $815^{\circ} \mathrm{C}$. The strain/time behavior resembled that for the creep experiment at $\sigma=175 \mathrm{MPa}$ and $\mathrm{T}=815^{\circ} \mathrm{C}$ which is overlaid on the plot. 